\title{
RNA/DNA co-analysis from bloodstains on aged polyvinyl-alcohol gloves prepared for securing evidence from the hands of victims of fatal gunshot injuries
}

\author{
Melanie Grabmüller ${ }^{1} \cdot$ Cornelius Courts $^{1,2} \cdot$ Burkhard Madea $^{1} \cdot$ Tim Eichhorst $^{1}$ • \\ Christian Schyma ${ }^{3}$
}

Received: 6 March 2017 / Accepted: 30 August 2017

(C) Springer-Verlag GmbH Germany 2017

\begin{abstract}
In contrast to cumulative techniques (e.g., tape-lift) for qualitative gunshot residues (GSR) analysis, topographic methods are commonly applied to preserve the integrity of evidence from a shooter's or victim's hand in cases of gunrelated crimes. Topographic sampling techniques employing adhesive foils, latex, or the polyvinyl alcohol (PVAL) method enable unambiguous sampling of biological and nonbiological trace material while preserving its spatial distribution and relation to each other. The PVAL method in particular allows for a topographically veridic and quantitative conservation of traces of GSR and biological stains that are embedded in the PVAL glove, because it completely removes these traces from the hand. The present study investigated the success rates of STR profiling and the detection of blood and brain-specific gene expression from minimal traces of blood splatter as well as parallel to the positive detection of gunshot residues embedded in 17 PVAL gloves taken from the hands of deceased persons in the context of homicide cases in the period between 1996 and 2003. The water-soluble PVAL
\end{abstract}

Electronic supplementary material The online version of this article (https://doi.org/10.1007/s00414-017-1687-2) contains supplementary material, which is available to authorized users.

Melanie Grabmüller

Melanie.Grabmueller@ukbonn.de

1 Institute of Legal Medicine, University of Bonn, Stiftsplatz 12, 53111 Bonn, Germany

2 Insitute of Forensic Medicine, University of Schleswig-Holstein Kiel, Arnold-Heller-Straße 12, 24105 Kiel, Germany

3 Institute of Forensic Medicine, University of Bern, Bühlstraße 20, 3012 Bern, Switzerland matrix is shown to be fully compatible with successful STR profiling and the detection of blood- and brain-specific miRNA expression, even after up to 20 years of storage, demonstrating that this sampling technique offers advantages compared to other more simplistic sampling methods like taping.

Keywords Polyvinyl alcohol method · PVAL · Gunshot residues $\cdot$ Bloodstains $\cdot$ RNA/DNA co-analysis $\cdot$ Blood- and brain-specific expression

\section{Introduction}

It is widely accepted that in cases of firearm-related fatalities, a systematic investigation at the scene of death is indispensable to differentiate between self-inflicted [1-3], intentionally or accidentally caused gunshot injuries. In such cases, it is important that results of the analysis of available residual non-biologic material (e.g., gunshot residues (GSR)) caused by firearm discharge, and/or biological material ejected from the entrance wound into the direction of the firearm, i.e., "backspatter," are evaluated integratively. Notably, traces of backspatter have been demonstrated to be retrievable from inside surfaces of firearms [4-11], from the shooter's hand [12, 13] (also GSR) and the shooter's surroundings and may be of considerable value in forensic crime scene investigations and in reconstructing the course of events. Biological material located on the shooter's hand is an important cue indicating self-inflicted gunshot injury; however, the presence of firearm-related bloodstains and GSR on an individual's hand does not necessarily prove that this person did indeed discharge a firearm.

Topographic sampling utilizing adhesive foils or tapes, latex, or the polyvinyl alcohol (PVAL) technique, first 
introduced in 1993 by Merkel and Mailänder [14], represents an essential procedure for sampling GSR or biological material from a shooter's hand. For the PVAL technique, a water soluble liquid polymer is used to cover the hands of suspects or victims for in situ preservation of residual evidence which allows for a representative conservation of trace materials by recording the positional information of the particles and backspatter on the hands. This method is suitable for the detection and characterization of GSR [14-17], and while its compatibility with singleplex STR typing has already been demonstrated [18], it remains to be seen whether it is appropriate for multiplex STR profiling and simultaneous investigation of co-extracted miRNA from backspatter retained from PVAL gloves.

The interest in RNA analysis steadily increased during the last decade in the forensic field. In 1984, Oehmichen et al. [19] were first to mention RNA in the forensic literature in their description of post-mortem RNA synthesis. Ten years later, Phang et al. [20] introduced gene expression analysis via reverse transcription PCR to forensic molecular biology. Following methodological advances in RNA analysis and quantification, forensic laboratories began to adopt RNA based techniques and more and novel applications employing mRNA and miRNA for forensic body fluid identification and organ tissue identification were being explored [21-25]. MicroRNAs (miRNA) are more stable and substantially less prone to degradation than mRNA because of their short size (18-24 bp) and exhibit less recognition sites for nucleases which are crucial advantages in the investigation of forensic type samples.

Therefore, the aim of the present study was to systematically investigate the feasibility of forensic analysis of miRNA and DNA that have been isolated from bloodstains and biological material embedded in PVAL gloves of the hands of persons involved in cases of homicide by gunshot.

\section{Material and methods}

\section{Samples and ethics}

Samples from polyvinyl gloves from the left and right hand of nine deceased persons of fatal gunshot injuries comprising seven homicides, one homicide-suicide, and one accident where collected between 1996 and 2003. The gloves were prepared as described elsewhere [14, 17]. Altogether, 17 PVAL gloves were examined, representing eight cases with gloves prepared from both hands and one case with a glove prepared only from the right hand.

The study protocol was reviewed and approved by the ethics committee of the Hospital of the University of Bonn.

\section{Forensic analysis of GSR}

\section{Preservation of evidence and detection of gunshot residues}

To examine GSR, PVAL gloves (Fig. 1) were treated with 2\% tartaric acid and saturated sodium rhodizonate solution. After drying, purple-, red-, or orange-colored particles were detected using a stereo microscope Stemi $2000 \mathrm{C}$ (Carl Zeiss Microscopy, Oberkochen, Germany) at 20- to 40-fold magnification. Samples of these particles were examined by nondestructive energy dispersive X-ray fluorescence analysis (Eagle $\mu$-Probe II, EDAX Inc., Mahwah, USA) to verify GSR characteristic elemental composition. After closure of the criminal investigation by the prosecutor, the samples were archived in a dry and dark environment. No further examination had been done until the molecular genetic analyses were performed.

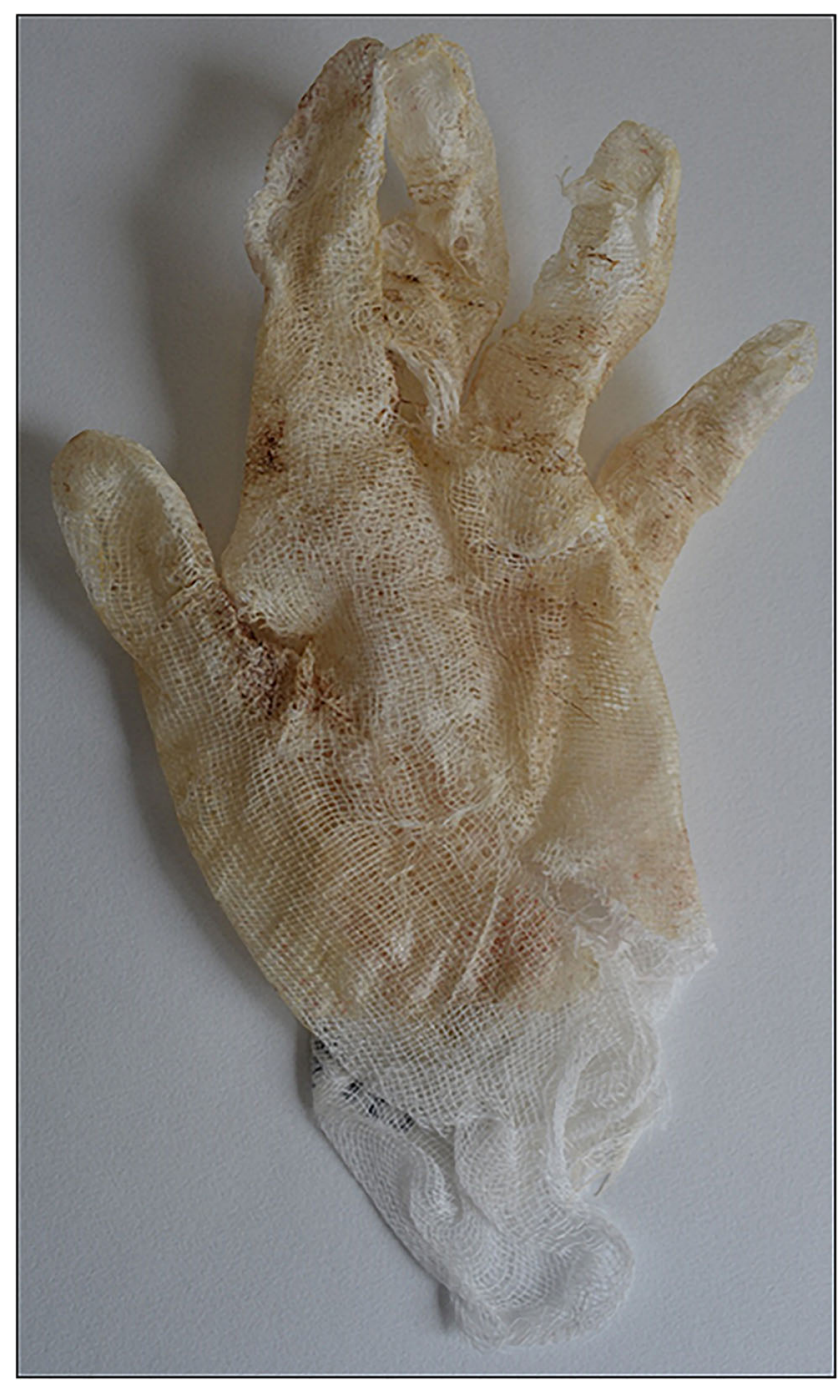

Fig. 1 PVAL glove from the right hand of a homicide victim (case \#1) with blood-stained area between thumb and forefinger (palm shown, glove turned inside out) 


\section{Molecular genetic analysis}

\section{Sampling procedure}

To prevent a possible bias the investigations were performed by experimentators blinded to case histories, involved persons, weapons, and shooters.

First, for the RNA/DNA co-analysis and DNA analysis, gloves were examined macroscopically, and areas containing visible stains suspected to contain blood were cut out into small pieces (approximately $1 \mathrm{~cm}^{2}$ ) using sterile scissors (Fig. 2). Selected areas from each glove that were free of any visible trace of blood or other material were also cut out (N1) and, together with samples of excess gauze that had not been treated with PVAL (N2), served as negative controls for the RNA/DNA co-analysis. For each glove, both separate and pooled samples (pooling together several cuttings) were generated and examined separately. For the sake of maximal sample retention, presumptive blood tests were performed after selecting the samples for RNA/DNA co-extraction and DNA analysis. From each glove, one visible minimal trace suspected to contain blood was cut out. The identification of blood was performed using the Hexagon OBTI® test (Gesellschaft fuer Biochemica und Diagnostic mbH, Wiesbaden, Germany) which detects human hemoglobin.

\section{RNA extraction, quantification, and integrity assessment}

Prior to all RNA processing, all surfaces, instruments, and devices employed in the processes were thoroughly cleansed using RNase-Zap ${ }^{\circledR}$ (Ambion, Austin, TX, USA) and Roti®Nukleinsäurefrei (Carl Roth, Karlsruhe, Germany) to remove

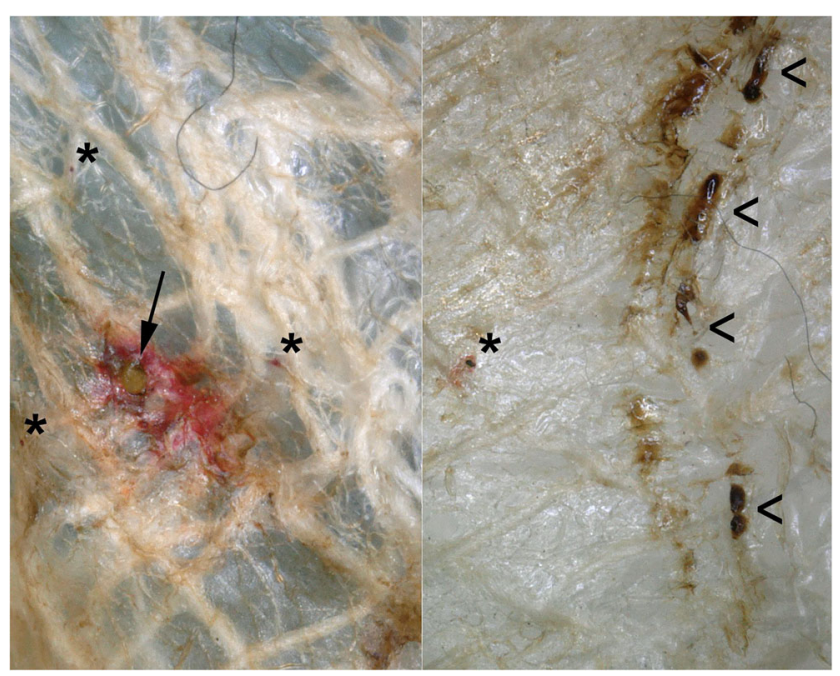

Fig. 2 Dorsum of the right glove of case \#9. GSR particles $<10 \mu \mathrm{m}(*)$. Powder particle (arrow) embedded in purple red rhodizonate positive area (lead confirmed). Minimal spatters $(<)$ of biological material (blood positive presumptive test) used for the nucleic acid analysis. all traces of ambient RNases and nucleic acid contaminations. Only RNase-free reagents and plastic consumables were used.

Nucleic acids were extracted using the NucleoSpin ${ }^{\circledR}$ miRNA Kit (Macherey-Nagel, Düren, Germany) according to the provided small RNA protocol with minor changes which had previously been shown to be well suited for coextracting DNA and RNA from forensic type samples [26]. Briefly, cuttings were incubated for 10 min with $350 \mu$ lysis buffer at room temperature, and NucleoSpin ${ }^{\circledR}$ Forensic Filters (Macherey-Nagel) were then used to separate the liquid nucleic acid containing lysate from discardable solid material by centrifugation at $21000 \times g$ for $3 \mathrm{~min}$. The lysate was then processed according to the protocol, and small RNA was finally eluted in $40 \mu \mathrm{l}$ of nuclease-free water pre-heated to $95{ }^{\circ} \mathrm{C}$. All RNA extracts were stored at $-80{ }^{\circ} \mathrm{C}$ until further processing.

Quantity and quality of RNA were measured using QuantiFluor ${ }^{\circledR}$ RNA Dye with the Quantus ${ }^{\mathrm{TM}}$ Fluorometer (both Promega, Mannheim, Germany) and the RNA 6000 Pico Kit with an Agilent 2100 Bioanalyzer (both Agilent, Böblingen, Germany), respectively. For both methods, $1 \mu \mathrm{l}$ of RNA extract was used, and all measurements were performed according to the manufacturers' prescriptions. RNA quality is represented by the "RNA integrity number" (RIN) [27]. Based on quantification results, all individual samples were diluted to a final concentration of $2 \mathrm{ng} / \mu \mathrm{l}$ with RNasefree water. If RNA yield was too low to be detected fluorometrically, the maximum input volume for reverse transcription reactions was used instead.

\section{DNA (co-) extraction, quantification, and STR profiling}

Co-extraction of DNA was performed for each sample by diverting $20 \mu \mathrm{l}$ of its DNA containing RNA lysate to the DNA extraction procedure of the PrepFiler ${ }^{\circledR}$ Forensic DNA Extraction Kit (Life Technologies, Darmstadt, Germany) processing it according to manufacturer's instructions.

DNA extraction of pooled samples was performed using the PrepFiler® Forensic DNA Extraction Kit (Life Technologies) according to manufacturer's prescription. All DNA extracts were then stored at $-20{ }^{\circ} \mathrm{C}$ until further processing.

DNA concentration, degradation, and the presence of PCR inhibitors were measured by quantitative PCR (qPCR) using the PowerQuant ${ }^{\mathrm{TM}}$ System (Promega, Mannheim, Germany) as recommended by the manufacturer on an ABI Prism 7500 Sequence Detection System (Life Technologies).

DNA profiling was performed for selected samples by STR multiplex PCR using the PowerPlex ${ }^{\circledR}$ ESI/ESX 17 System (Promega) according to the provider's prescriptions. Input amounts of DNA were used: separate samples between $11 \mathrm{pg}$ and $16 \mathrm{ng}$, pooled samples between 7 and $500 \mathrm{pg}$ 
(RNA/DNA co-extraction) and pooled samples from DNA extraction between $53 \mathrm{pg}$ and $10 \mathrm{ng}$.

PCR products were detected on an ABI 310 Genetic Analyzer (Life Technologies). GeneMapper v3.2.1 software (Life Technologies) was used for raw data analysis and DNA profile compilation. The analytical threshold for a positive signal was set at 50 RFU.

\section{Selection of blood- and brain-specific miRNA and reference genes for $\mathrm{qPCR}$ data normalization}

Based on previous work [28-31], the following blood- and brain-specific miRNAs were chosen for the detection of blood and brain tissue: $m i R-451 a$ (blood) and $m i R-124 a$ (brain tissue) (Table 1).

MiR-191 was chosen as best suited reference gene to serve as an endogenous control for the normalization of blood- and brain-specific miRNA expression data (Table 1). This choice was based on a selection procedure employing three wellestablished computational algorithms, geNorm [33], NormFinder [34], both implemented in the GenEx v6 software (multiD Analyses AB, Goteborg, Sweden) and the Excel-based BestKeeper [35]. Sauer et al. [36, 37] established a reliable and reproducible strategy for qPCR data normalization from forensically relevant body fluids and organ tissues in forensic type samples. They provided us with their raw expression data of nine carefully preselected candidate reference genes in dried blood stains and ten selected candidate reference genes for brain tissue from which the most stably expressed gene was determined to be in both cases miR-191 (data not shown) (reference genes: see Supplementary Table 1) [38-40].

\section{Reverse transcription and $q \mathrm{PCR}$}

Complementary DNA (cDNA) was synthesized from miRNA using the TaqMan® MicroRNA Reverse Transcription Kit employing target-specific stem-loop primers (both Life Technologies) in a total volume of $15 \mu \mathrm{l}$. Each miRNA reverse transcription (RT) reaction comprised $10 \mathrm{ng}$ of total RNA, 1× RT Primers, 50 U MultiScribe ${ }^{\mathrm{TM}}$ Reverse Transcriptase, $1 \mathrm{mM}$ dNTPs, $3.8 \mathrm{U}$ RNase Inhibitor, and $1 \times$ RT buffer.
All RT reactions were performed on a T3 Thermocycler (Biometra, Göttingen, Germany) with the following cycling conditions: $16^{\circ} \mathrm{C}$ for $30 \mathrm{~min}, 42^{\circ} \mathrm{C}$ for $30 \mathrm{~min}$, and $85^{\circ} \mathrm{C}$ for $5 \mathrm{~min}$.

To detect potential contaminations with genomic DNA or of our reagents, RNA extraction negative controls, RT(-) controls (i.e., RT reactions without reverse transcriptase) and $\mathrm{H}_{2} \mathrm{O}$ controls (i.e., RT reactions with water instead of RNA template) were set up, respectively. RNA was kept on ice during processing, and RT reaction products were stored at $-20^{\circ} \mathrm{C}$ until further proceedings.

QPCR was performed using target-specific TaqMan® Assays (Life Technologies) (Table 1) for the selected bloodand brain-specific miRNA and the reference gene. Each $20 \mu \mathrm{l}$ reaction contained $1.3 \mu \mathrm{l}$ of the respective RT reaction product, 1 x TaqMan® Universal PCR Master Mix, No AmpErase ${ }^{\circledR}$ UNG (Life Technologies) and $1 \mathrm{x}$ TaqMan®Assay. All reaction components were kept on ice during processing.

All sample/assay combinations were run in technical triplicates. All qPCR reactions were conducted in MicroAmp® Optical 96-Well Reaction Plates on an ABI Prism 7500 Sequence Detection System (both Life Technologies) with the following qPCR cycling conditions: $95{ }^{\circ} \mathrm{C}$ for $10 \mathrm{~min}$, followed by 40 cycles with $95^{\circ} \mathrm{C}$ for $15 \mathrm{~s}$ and $60^{\circ} \mathrm{C}$ for $1 \mathrm{~min}$.

To normalize inter-run variation between $\mathrm{qPCR}$ reaction plates, the internal positive control (IPC) from the PowerQuant ${ }^{\mathrm{TM}}$ System (Promega) was used as an inter-plate calibrator. Raw fluorescence data was collected during the $60{ }^{\circ} \mathrm{C}$ step by the SDS software v2.0.6 (Life Technologies) and then exported for further analysis.

\section{Data analysis, normalization, statistics, and MIQE compliance}

To calculate quantification cycle $\left(\mathrm{C}_{\mathrm{q}}\right)$-values and amplification efficiencies from raw data from SDS spread sheet exported $\mathrm{R}_{\mathrm{n}}$-values, the LinRegPCR analysis program v2015.1 [41] was applied. Efficiencies outside 5\% of the group median were excluded from mean efficiency calculation. For the calculation of $\mathrm{C}_{\mathrm{q}}$-values, a common threshold value was set to $-0.7 \log$ (fluorescence). Sample

Table 1 Specifications of the RNA Assays

\begin{tabular}{llllll} 
Official gene symbol & NCBI-/miRBase-mature sequence accession & TaqMan assay ID & $\begin{array}{l}\text { Small RNA sequence } \\
\text { (amplicon length in base pairs) }\end{array}$ \\
\hline hsa-miR-451a & MIMAT0001631 & 001141 & AAACCGUUACCAUUACUGAGUU (22) & [28, 29] \\
$h s a-m i R-124 a$ & MIMAT0000422 & 001182 & UAAGGCACGCGGUGAAUGCC (20) & [30] \\
$h s a-m i R-191-5 p$ & MIMAT0000440 & 002299 & CAACGGAAUCCCAAAAGCAGCUG (23) & {$[31]$} \\
\hline
\end{tabular}

NCBI National Center for Biotechnology Information, miRBase microRNA database [32] 
replicates exhibiting $\mathrm{C}_{\mathrm{q}}$-values deviating more than one unit from the mean of the triplicates were excluded from further processing. Normalization of computed $\mathrm{C}_{\mathrm{q}}$-values of target-specific miRNA was performed using the GenEx software v6 (multiD Analyses AB). Pre-processing of qPCR encompassed the following steps in the given order: efficiency correction, averaging of technical qPCR replicates, and normalization with reference genes resulting in $\Delta \mathrm{C}_{\mathrm{q}}$-values. A normalized $\mathrm{C}_{\mathrm{q}}$-value $\left(\mathrm{C}_{\mathrm{q}, \mathrm{n}}\right)<35$ was considered to indicate successful PCR implying a targetspecific signal and thus RNA quantity and quality suitable for expression analysis.

Data analysis, interpretation, and statistical calculations were performed using MS EXCEL and SPSS software v.22 (SPSS Inc., Chicago, IL, USA).

To facilitate reliable and unequivocal interpretation of the qPCR results reported herein, all information that is rated "essential" according to the MIQE guidelines [42] is reported, where applicable.

\section{Results}

\section{GSR analysis performed 1996-2003}

In sampling (non-)biological material from the hands of seven homicide victims, one accident and one suicide case, the polyvinyl alcohol method was used as the method for the preservation of evidence.

Although the examined PVAL gloves were especially obtained from persons killed by third in the half of the cases, GSR particles had been detected. However, no GSR pattern had been found that indicated firing or handling a gun. Only in case \#9 where the suspect first shot his wife and commit suicide afterwards by contact shot to the head, the GSR pattern on the PVAL of the right hand was found compatible with shooting (Fig. 2).

\section{Presumptive blood test}

The interpretation of a trace pattern is often of great importance for the reconstruction of an event. This also includes knowledge of the type of examined trace material. In the present study, it was all the more important, because the PVAL had been stored for many years so that the color contrasts of the stains had faded.

In case of 17 examined gloves, only five gloves (29\%) exhibited a positive signal for the presumptive blood test, including two gloves (case \#1, left hand and case \#3, right hand) which showed a weak positive signal (Supplementary Fig. 1).
Quantification and STR profiling of (co-)extracted DNA

Secured biological material was collected from various locations of the PVAL gloves (Figs. 1 and 2 and Table 2). Samples were either analyzed separately or pooled (combining several cuttings) and then analyzed.

DNA was quantifiable in 76 and $94 \%$ of samples analyzed separately and pooled after RNA/DNA co-extraction, respectively. Only in case \#8 was no DNA detectable from the right hand.

Pooled samples which had been supplied to DNA extraction exhibit for all stains quantifiable DNA concentrations. However, a wide range of DNA concentrations was observed between samples from different PVAL gloves. The highest DNA concentration $(0.9 \mathrm{ng} / \mu \mathrm{l})$ was obtained in a sample recovered from the left glove of case \#4 whereas the lowest DNA amount $(0.2 \mathrm{pg} / \mu \mathrm{l})$ was measured in four samples collected from the right PVAL glove of case $\# 2$ and left and right glove of case \#9. Notably though, DNA yields were low in average with no detectable inhibitions but different extents of degradation (data not shown).

After RNA/DNA co-extraction, only $16 \%$ of samples contained more than 100 pg DNA in $17.5 \mu \mathrm{l}$ (maximum input volume for multiplex PCR reaction) which had reliably proved sufficient for successful STR profiling in our hands.

By contrast, after DNA extraction, one sample (case \#8, right hand) contained less than $100 \mathrm{pg}$ DNA in $17.5 \mu \mathrm{lmul}$ tiplex PCR reaction volume.

Then, to assess the success rate of STR typing with samples collected from PVAL gloves, DNA profiles were generated from selected samples using PCR input amounts between $7 \mathrm{pg}$ and $16 \mathrm{ng}$ of DNA and were rated according to the following result categories:

“++," full STR profiles (17 of 17 possible STR systems), “+," identifiable profiles (at least 8-16 of 17 possible STR systems), and "-," not identifiable profiles (less than 8 of 17 possible STR systems).

\section{RNA/DNA co-extraction}

"++" was observed in three cases for STR PCR input amounts between $500 \mathrm{pg}$ and $1.6 \mathrm{ng}$ of DNA. In 58\% of tested samples from left and right gloves, DNA profiles were rated " + " with STR PCR input amounts of $>11 \mathrm{pg}$ and up to $1.0 \mathrm{ng}$ (except for \#6 R-2, which produced a "-" with an input DNA amount of $32 \mathrm{pg}$ ). STR profiling was unsuccessful (“-”) for $30 \%$ if the STR PCR input amount of DNA was between 7 and $26 \mathrm{pg}$.

\section{DNA extraction}

Samples with STR PCR input amounts between 1.0 and $10 \mathrm{ng}$ of DNA generated full STR profiles ("++") in more than half of the cases. DNA profiles were rated " + " in $41 \%$ of samples 


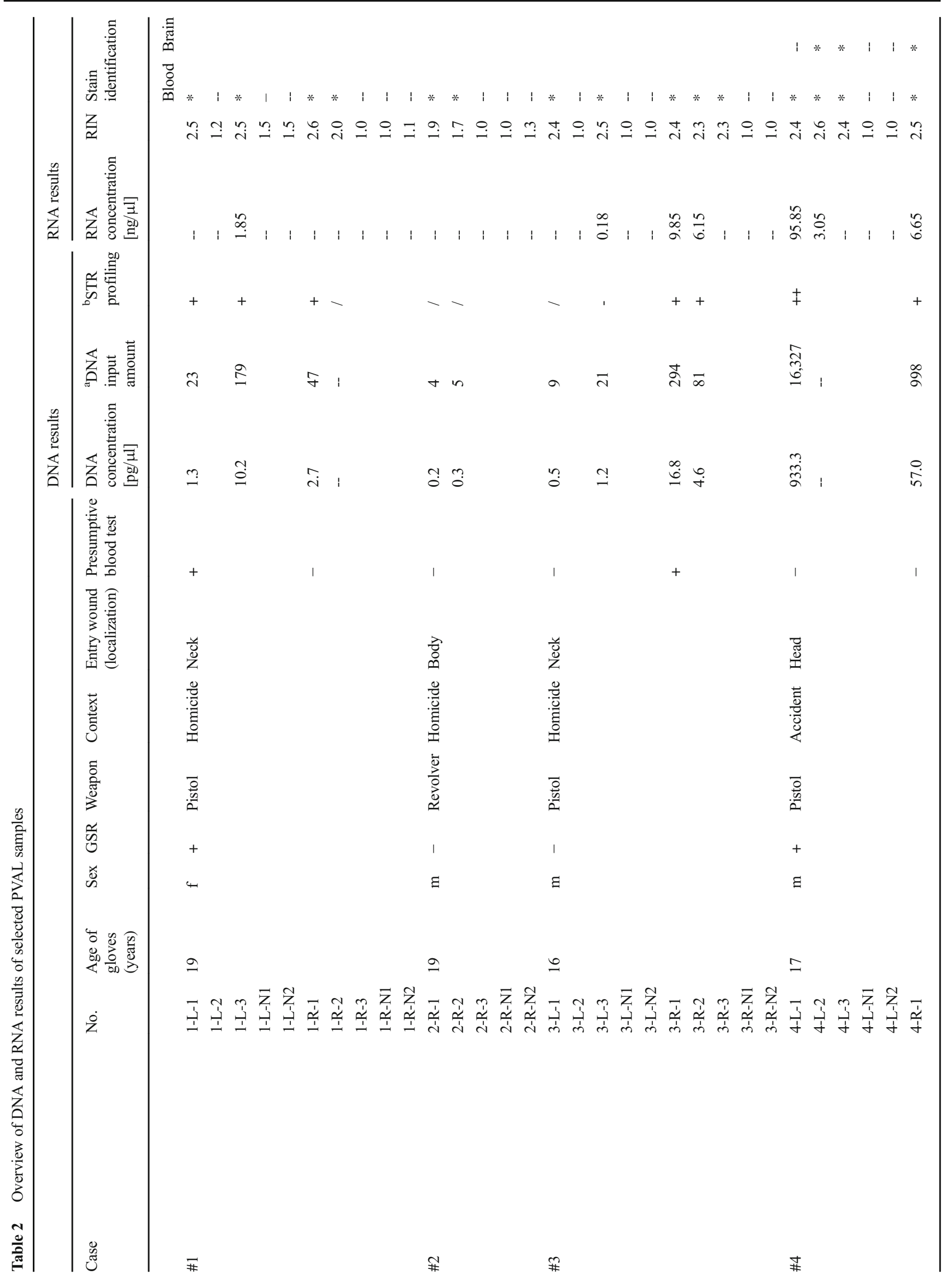




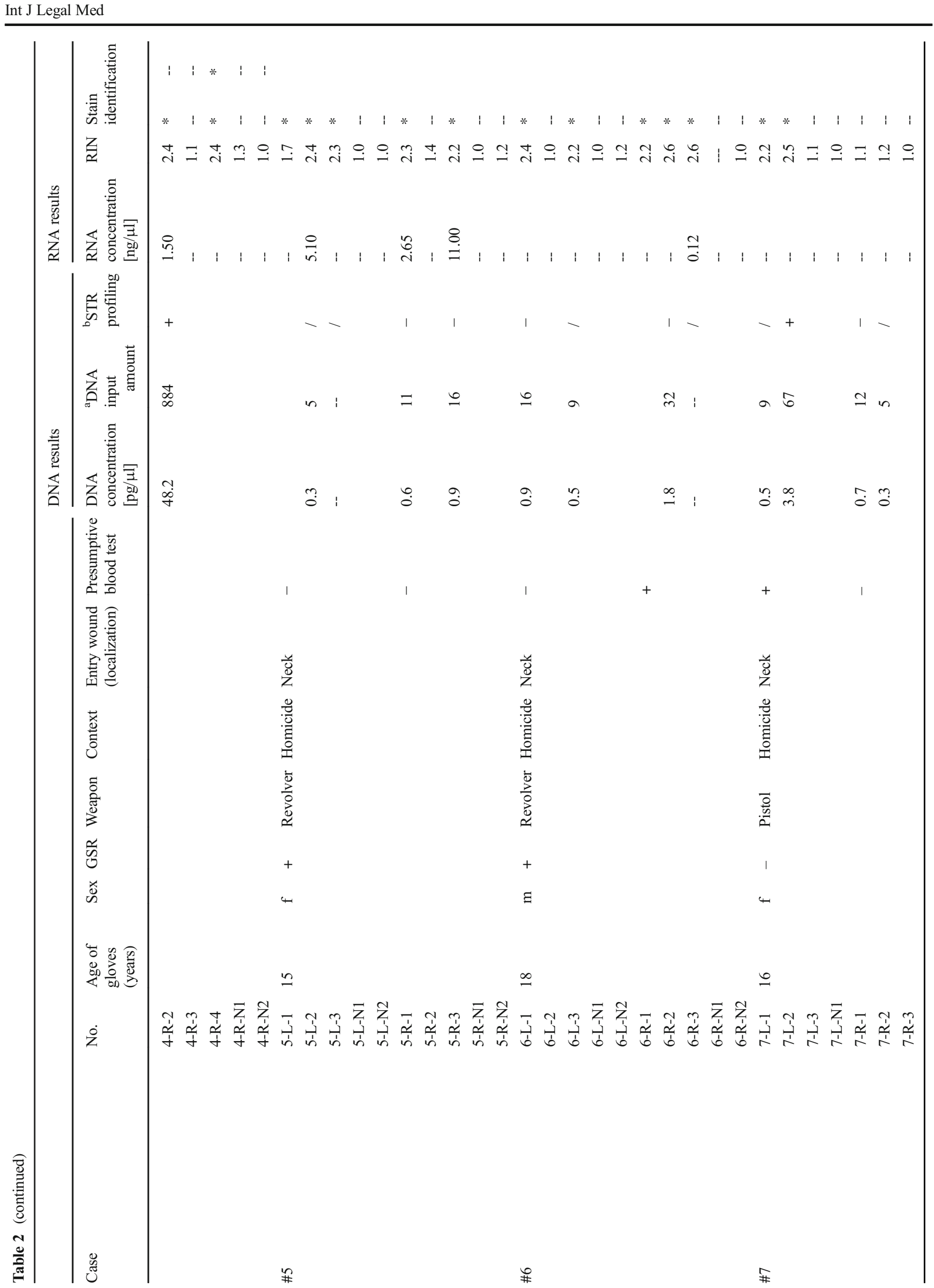




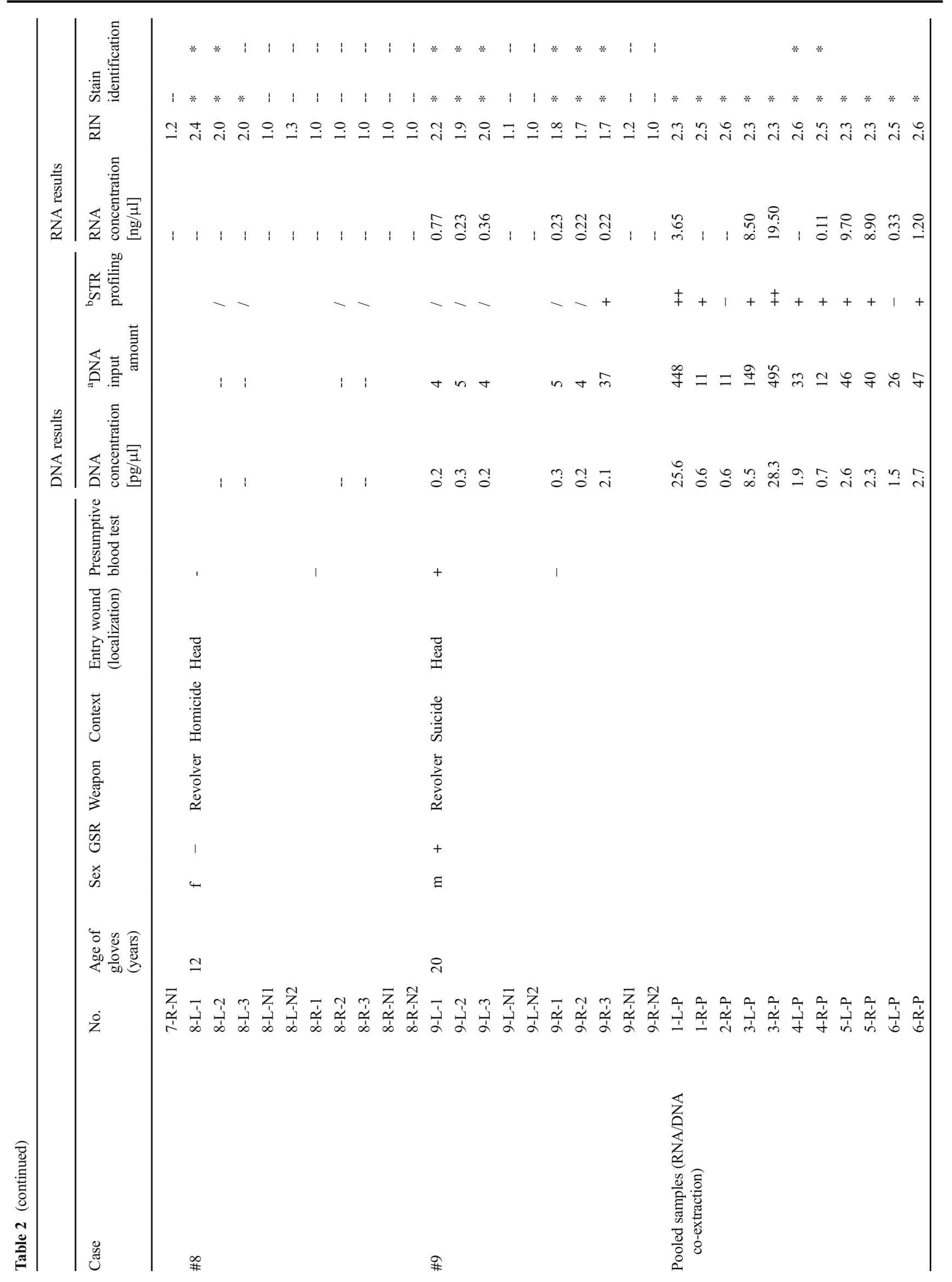




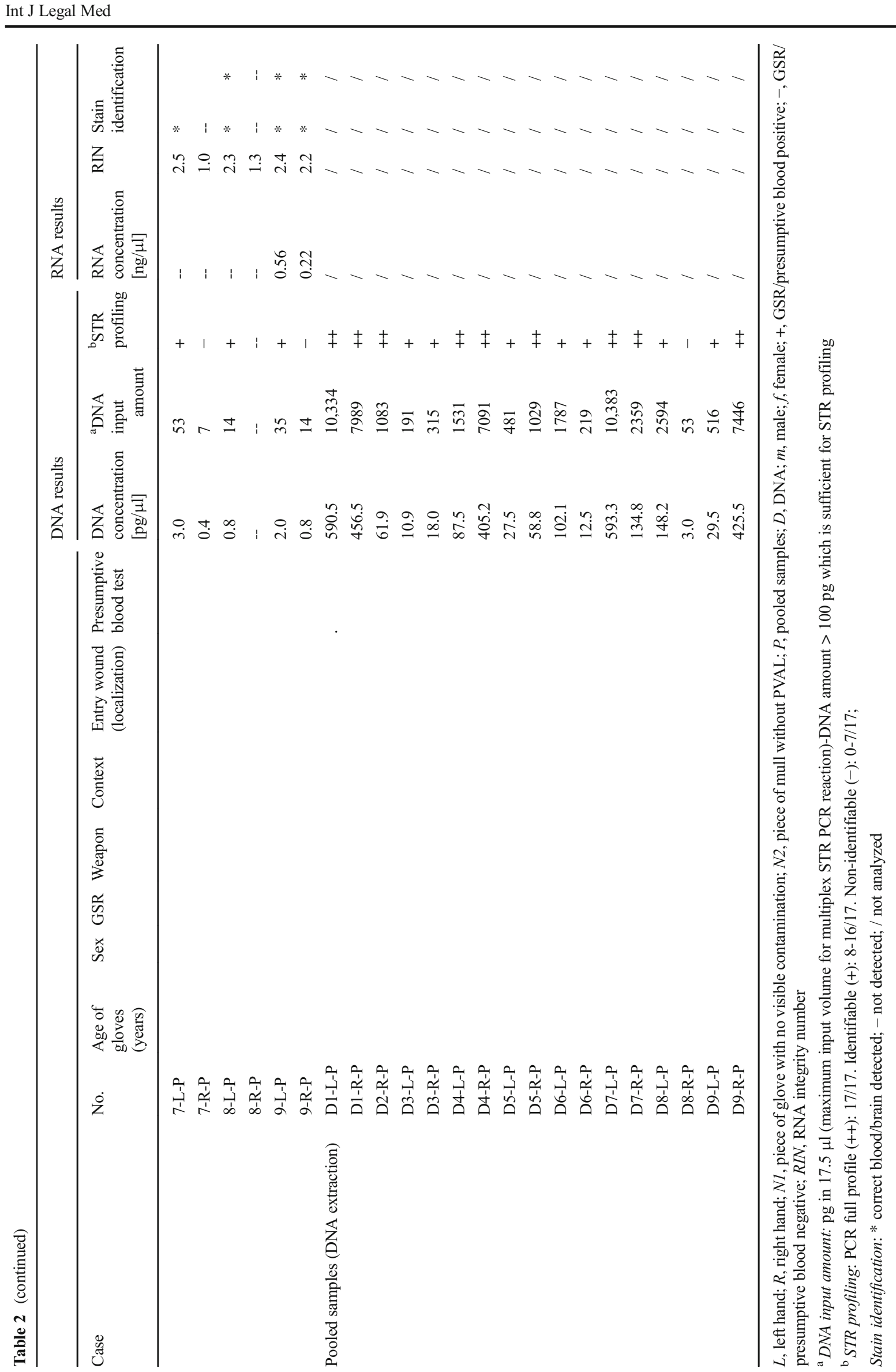


generated with STR PCR input amounts > $190 \mathrm{pg}$ and up to $500 \mathrm{pg}$. Only in one case (\#8 right hand) was STR profiling unsuccessful "-" with the STR PCR input amount of DNA being $53 \mathrm{pg}$.

In case \#9 where the PVAL glove was sampled from the shooter's hand, all examined traces exhibited the DNA profile of the shooter and not from the victim. Table 2 summarizes these results.

\section{Quantity and integrity of RNA}

Overall and analogous to DNA, small RNA exhibited considerable variation in terms of quantity but only minor variation in terms of, generally low, quality (RIN) as expected for forensic samples of this type between the different cases. The highest RNA yield $(95.85 \mathrm{ng} / \mu \mathrm{l})$ was obtained for a sample recovered from the left glove of case \#4. Only in $28 \%$ of samples $(21 \%$ of separately analyzed samples and $59 \%$ of pooled samples, respectively) a RNA concentration could be determined.

For the assessment of RNA quality, RIN values were established. Overall, regardless of the age of the samples, RIN values ranged between 1.0 and 2.6. Pooled samples exhibited RIN values between 2.2 and 2.6 (except cases \#7 and \#8; both right hands). In the subsequent qPCR-based bloodand brain-specific miRNA expression analysis, all samples with an RNA quality $>1.7$ produced a significantly positive signal for blood and brain tissue, and vice versa $(p=0.000)$. Although cases \#4 (both hands) and \#8 (right hand) exhibited RIN values of 2.4 and 2.0, respectively, no brain-specific expression could be determined.

Quantification and quality results are summarized comprehensively in Table 2 .

\section{Expression analysis of miRNA}

A downstream qPCR analysis was used to assess the general suitability of forensic RNA extracted from selected samples of backspatter that was recovered from PVAL gloves to produce blood- (miR-451a) and brain- (miR-124a) specific miRNA expression levels.

Although small RNA was not detectable fluorometrically in some samples, fluorescence-based detection of blood- and brain-specific miRNA expression via qPCR was successful. Normalized expression of $m i R-451 a$ that was considered to be indicative of blood $\left(\mathrm{C}_{\mathrm{q}, n}<35\right)$ was detected in $77 \%$ of all samples: $88 \%$ for pooled samples and $73 \%$ for separately analyzed samples, respectively. Only in cases \#7 and \#8 (both right gloves) was the detection of blood-specific miRNA expression not successful (Table 2).

Additionally, for three cases (\#4, \#8, and \#9) in which headshots had been delivered, brain-specific miRNA was examined. Overall, brain-specific miRNA could be detected on at least one sample of each hand, expect case \#8 (right hand pooled sample).

In contrast, all selected areas from each glove free of any visible traces of blood or other material (Table 2: N1, N2) were negative for blood- and brain-specific miRNA expression. Furthermore, all negative controls (extraction negative, $\mathrm{RT}(-)$ and $\left.\mathrm{H}_{2} \mathrm{O}\right)$ showed no or unspecific results $\left(\mathrm{C}_{\mathrm{q}}>35\right)$ for all tested samples.

\section{Discussion}

In firearm-related fatalities, the differentiation between homicide, suicide, and accident can sometimes be exceedingly difficult, and a final assessment of the events can only be reached after a detailed analysis of all aspects and circumstances of the incident. The reconstruction is not only to be based on the analysis of the death scene but requires a complex and integrative analysis of all findings in the given case including nonbiological material (e.g., gunshot residues), biological material (e.g., blood stains and backspatter), results of medico-legal autopsy, and forensic chemical analysis. Therefore, the aim of the present study was to investigate the simultaneous extraction and forensic analysis of miRNA and nuclear DNA from aged traces of bloodstains that had been collected with the PVAL method from hands of victims of fatal gunshot injuries after GSR analysis had been done more than 12 years ago.

For the assessment of the value of a particular piece of GSR evidence in linking a person to a crime, it is important to distinguish whether or not that person did indeed fire a gun in a specific situation. The topographic PVAL technique in contrast to other methods reproduced a true image of the original findings on the hand [18]. The position and spatial relations between all (non-)biological traces can precisely be reconstructed at any time, as they are accurately transferred form the hand to the glove. However, the detection of GSR on a person's hand or any other surface can also occur if a firearm has been discharged in proximity or after contact with a surface that is contaminated with GSR. This then can lead to false interpretation of the circumstances of events.

Although the PVAL gloves were sampled from eight persons who were killed by third, in four cases, GSR were detectable after forensic chemical and physical analysis. The origin of GSR on the hand/s of some victims might be explained by close range shots fired to the back of the victims' head or neck region so that particles of the discharge could reach their hands. However, only in case \#9 where the husband had killed his wife, GSR showed a typical pattern indicating a shooter's hands. Therefore, a detailed reconstruction of the circumstances of firearm-related death has to go beyond the detection of GSR and should include analysis of biological material.

Hence, before commencing molecular genetic analysis, it should first be assessed what type of trace material is present. 
Presumptive preliminary tests are intended to enable the identification of a stain and are conducted after visual examination. Conventional methods for blood identification include immunological, chemical, and enzymatic tests. These tests vary greatly in terms of sensitivity and specificity and comparably large amount of sample material are required to perform these tests which are problematic, since the amount of evidential biological material is usually very limited in forensic casework and especially in backspatter and bloodstain analysis. The Hexagon OBTI® test is known as a rapid and highly specific and sensitive one-step immunochromatographic assay for the detection of human hemoglobin and was used for qualitative detection of human blood on the PVAL gloves. Hochmeister et al. [43] found that an immunochromatographic 1-step test is robust and suitable for forensic analyses, being human specific. However, in our examination, perhaps due to the minute amount or time-wise degradation of trace material, the presumptive blood test gave out a positive result only in less than a third of the samples. In contrast, microRNA-based body fluid identification (BFI) has been shown to be very sensitive and robust against degradation and can be performed in parallel to DNA analysis without consuming any additional trace material [19]. RNA/DNA coextraction and subsequent miRNA-based BFI can outperform conventional tests, providing a direct link to the crime scene stain. Combining these analyses can then answer of which individual the trace originates (individualization) and what kind of trace material it is (contextualization).

STR profiling is considered "gold standard" for DNA-based identification because of its robustness and high power of discrimination and the analysis of DNA, comprising quantification and the generation of STR profiles, from authentic material from homicide cases sampled using the PVAL method produced reliable results for $\sim 20$ year old trace material. Our findings confirm, what had already been pointed out by Schyma et al. [18]. They investigated 13 PCR systems including seven singleplex STR systems (HumTH01, HumVWA31, HumFES, HumF13B, HumFGA, D1S80, and CD4), five structure polymorphisms (LDLR, GYPA, D7S8, HBGG, and GC), and one VNTR system (HLA-DQ $\alpha$ ). Only five of these seven STR systems are still in use in contemporary multiplex STR kits, and only three (TH01, VWA, and FGA) are comprised by widely used highly robust next generation STR multiplex kits which had been developed for DNA analysis of small amounts of potentially degraded trace material in forensic laboratories. In 1999, a European Standard Set (ESS) of STR loci introduced [44], and there is a considerable difference concerning the power of discrimination between contemporary STR kits (comprising > 16 STR loci) and the kits available at that time (6 STR loci). Furthermore, we compared RNA/DNA co-extraction with the extraction of DNA alone. As expected, we obtained better results in STR profiling when using DNA extraction where a lower loss of DNA yield was observed as compared to RNA/DNA co-extraction. Thus, depending on the exact question concerning the circumstances of death, it should be assessed which analysis should be carried out. In such cases, it is advisable if be possible to sample several similar minimal traces located directly next to each other. From one sample, only DNA is then extracted from the other(s) DNA and RNA can be co-extracted. If in doubt e.g., if only one minimal trace is available, RNA analysis may be put on hold; alternatively, if the identity of the person in question had already been clarified or can be clarified without the need of DNA profiling, RNA can be extracted for downstream analysis instead. In summary, sampling biological material employing the PVAL technique with subsequent STR profiling using STR kits can produce reliable DNA profiles suitable for forensic identification with no observable inhibition and compared to other techniques applicable to recover traces from persons involved in firearmrelated death e.g., adhesive tape the PVAL method produced superior results [45].

Besides standard DNA analysis, another important aspect in the reconstruction of the circumstances of a crime is the analysis of the pattern and composition of a stain, e.g., bloodstains, by RNA-based identification of body fluids and organ tissues. In this study, the presence of blood and in case of head shots especially brain tissue on hands of the deceased, sampled with the PVAL technique was assessed via the identification of blood- and brain-specific miRNA for the first time.

In general, the assessment of RNA integrity is an important step in RNA expression analysis if small fold-changes are to be detected. In case of forensic experiments, however, where the detection of much coarser differences (e.g., expression vs. no expression) is sufficient studies suggest that low RNA integrity values do not adversely affect RT-qPCR profiling results [47, 48], and no difficulties were encountered using similar types of specimens mimicking forensic evidence in identifying small nucleolar RNAs (snoRNAs) as reference genes [36]; hence, the recommendation of a minimum RIN of 7 for samples to be proceeded was disregarded [49, 50]. In our study, RNA integrity was measured using the 2100 Bioanalyzer which employs microfluidic electrophoretic separation of RNA by molecular weight and fluorometric detection generating an electropherogram [27]. Based on these measurements, the software then calculates the RIN as described in the "Material and methods" section. RNA samples with RIN values of 1.0 were considered as completely degraded, whereas RIN values of 10 indicate intact RNA molecules [27]. Minimal amounts of trace material aged up to 20 years had been investigated, and we measured RIN values between 1.0 and 2.6 which can probably be attributed to the presence of low template or old samples where RNA degradation occurs. We found that only samples with RIN values $\geq 1.7$ produced significantly positive blood- or brain-specific expression. Therefore, it seems inappropriate to completely exclude a sample from molecular analysis because of insufficient or 
poor RNA quality if a RIN of 7 is regarded as minimum. As expected, a rise in miRNA concentration was associated with lower RNA quality caused by the formation of small RNA fragments by degradation of longer RNAs which were falsely interpreted as miRNA, as the Bioanalyzer method only considers fragment length.

Despite the partly unsuccessful fluorometric determination of RNA concentrations in samples from the PVAL gloves normalized blood- and brain-specific expression of $m i R$ $451 a$ and $m i R-124 a$, respectively, was successfully and correctly detected via qPCR in the tested samples. Brain-specific miRNA was detected on one hand of a victim, and on the PVAL glove in the suicide case \#9. In both cases, this finding was related to a contact shot to the head with brain injury. Our results are in line with the findings of Lux et al. [51] who in a pilot study proved the principle that the detection of brain specifically expressed RNA in samples of backspatter from firearm-related injuries may crucially support the inference that a head shot has occurred. Brain-specific miRNA was detected on at least one hand of the victims, hit in the head, and on the shooter's hand. A recent study investigated various miRNAs to differentiate between several different tissues and skin [52]. Furthermore, they investigated samples of backspatter recovered from inside surfaces of gun barrels after experimental shootings and correctly determined and differentiated brain, heart, and skeletal muscle tissue in 13 of 18 backspatter samples. Hence, our investigations confirmed these previous results. Furthermore, no correlation between DNA and RNA yield and age of sample or weapon type was observed. The pooling of all samples recovered from deceased in firearm-related crimes is deemed advisable and can enhance success rate of this method in routine casework.

In case \#9, we have demonstrated that sampled biological material from backspatter collected from the shooter's hand can successfully be subjected to the full bandwidth of chemical, physical, immunochromatographic and forensic nucleic acid analyses, encompassing nuclear DNA and miRNA-based body fluid, and organ tissue identification. We showed that after the person had committed suicide by a contact shot to the head blood-and brain-specific backspatter could be found on his hands. STR typing confirmed that the recovered traces of body fluid and organ tissue originated from him. We demonstrated that the correct detection of blood and brain tissue from the hands of deceased is feasible in up to 20 years old authentic trace material. The method is combining GSR and nucleic acid analysis for backspatter identification. The watersoluble PVAL matrix showed distinct advantages for successful extraction of nucleic acids in comparison with adhesive foils [45]. In case of adhesive foils, no successful STR profiling was obtained, because the glue reliably degrades DNA within a very short time. In contrast, the water-soluble PVAL matrix contains no solvents and facilitates better STR results. Another important difference between the adhesive foils and PVAL gloves is that too large a density of glue on the tape may interfere with the recovery of biological trace sample material and thus the process of genotyping, whereas too little of the adhesive substance results in lowered adhesiveness and hence reduced recovery of biological material. In addition, adhesiveness will also be reduced when collecting moist blood stains as applying the non-absorbent tape will smear the sample, reducing the efficacy of the collection of other biological material [16, 45]. Finally, the water-soluble matrix of PVAL is able to absorb a much greater quantity of the biological trace material present on the hands than adhesive foils can collect [16]. Consequently, the yield of nucleic acids will be greater, increasing the opportunity to identify the victim and the tissue injured.

\section{Conclusion}

In summary, we demonstrated that DNA and blood- and brain-specific miRNA from biological traces embedded in PVAL gloves recovered from case-related surfaces can successfully be recovered and analyzed even if only minimal amounts of material aged up to 20 years are available. However, to enhance the success rate of this method in routine casework, the pooling of all samples recovered from PVAL gloves used in firearm-related crimes appears to be advisable and generally advantageous. By demonstrating its high success rates, our results underscore the method's usefulness and recommend it above other non-destructive collection methods.

While we are confident to have shown that the PVAL method bears great potential for an application in forensic routine casework, ongoing research in this field is still necessary in our view to constantly expand the methodological repertoire, optimize, and adapt it to new methods of investigation such as forensic RNA analysis.

Acknowledgements This study was funded by DFG (Deutsche Forschungsgemeinschaft) (grant number CO992/4-1) and SNF (Swiss National Science Foundation) (grant number 310030E-147628/1). The expert technical assistance of Julia Brünig and Marion Sauer is also gratefully acknowledged.

Compliance with ethical standards The study protocol was reviewed and approved by the ethics committee of the Hospital of the University of Bonn.

Conflict of interest The authors declare that they have no conflict of interest.

\section{References}

1. Zwingli M (1941) Über Spuren an der Schiesshand nach Schussmit Faustfeuerwaffen. Arch Kriminol 108:1-26 
2. Heindl R (1944) Spuren an der Schiesshand nach Schussmit Faustfeuerwaffen. Arch Kriminol 114:75-88

3. Stone I, Petty C (1974) Examination of gunshot residues. J Forensic Sci 19(4):784-788

4. Courts C, Madea B, Schyma C (2012) Persistence of biological traces in gun barrels - an approach to an experimental model. Int J Legal Med 126(3):391-397

5. Schyma C, Madea B, Courts C (2013) Persistence of biological traces in gun barrels after fatal contact shots. Forensic Sci Int Genet 7(1):22-27

6. Courts C, Gahr B, Madea B, Schyma C (2014) Persistence of biological traces at inside parts of a firearm from a case of multiple familial homicide. J Forensic Sci 59(4):1129-1132

7. Schyma C, Lux C, Madea B, Courts C (2015) The 'triple contrast' method in experimental wound ballistics and backspatter analysis. Int J Legal Med 129(5):1027-1033

8. Grabmüller M, Schyma C, Euteneuer J, Madea B, Courts C (2015) Simultaneous analysis of nuclear and mitochondrial DNA, mRNA and miRNA from backspatter from inside parts of firearms generated by shots at "triple contrast" doped ballistic models. Forensic Sci Med Pathol 11(3):365-375

9. Grabmüller M, Cachée P, Madea B, Courts C (2016) How far does it get?-The effect of shooting distance and type of firearm on the simultaneous analysis of DNA and RNA from backspatter recovered from inside and outside surfaces of firearms. Forensic Sci Int 258:11-18

10. Schyma C, Bauer K, Brünig J, Courts C, Madea B (2017) Staining in firearm barrels after experimental contact shots. Forensic Sci Int 273:64-70

11. Schyma C, Brünig J, Madea B, Jackowski C (2016) Die Endoskopie des Waffenlaufes. Rechtsmedizin 26(3):224-229

12. Karger B, Nüsse R, Bajanowski T (2002) Backspatter on the firearm and hand in experimental close-range gunshots to the head. Am J Forensic Med Pathol 23(3):211-213

13. Kunz SN, Brandtner H, Meyer HJ (2015) Characteristics of backspatter on the firearm and shooting hand - an experimental analysis of close-range gunshots. J Forensic Sci 60(1):166-170

14. Merkel J, Mailänder R (1993) Über ein neues Verfahren zur Sicherung von Schmauchspuren an Schusshänden. Arch Kriminol 191:139-150

15. Schyma C (1996) Erfahrungen mit der PVAL-Methode in der rechtsmedizinischen Praxis. Arch Kriminol 197:41-46

16. Schyma C, Schyma P (1997) Der praktische Schusshandnachweis Die PVAL-Methode im Vergleich zu Abzügen mit Folie. Rechtsmedizin 7(5):152-156

17. Schyma C, Placidi P (2000) The accelerated polyvinyl-alcohol method for GSR collection-PVAL 2.0. J Forensic Sci 45(6): 1303-1306

18. Schyma C, Huckenbeck W, Bonte W (1999) DNA-PCR analysis of bloodstains sampled by the polyvinyl-alcohol method. J Forensic Sci 44(1):95-99

19. Oehmichen M, Zilles K (1984) Postmortem DNA and RNA synthesis. Preliminary studies in human cadavers. Rechtsmed 91(4): 287-294

20. Phang TW, Shi CY, Chia JN, Ong CN (1994) Amplification of cDNA via RT-PCR using RNA extracted from postmortem tissues. J Forensic Sci 39(5):1275-1279

21. Juusola J, Ballantyne J (2003) Messenger RNA profiling: a prototype method to supplant conventional methods for body fluid identification. Forensic Sci Int 135(2):85-96

22. Juusola J, Ballantyne J (2005) Multiplex mRNA profiling for the identification of body fluids. Forensic Sci Int 152(1):1-12

23. Zubakov D, Boersma AW, Choi Y, van Kuijk PF, Wiemer EA, Kayser M (2010) MicroRNA markers for forensic body fluid identification obtained from microarray screening and quantitative RTPCR confirmation. Int J Legal Med 124(3):217-226
24. Lindenbergh A, de Pagter M, Ramdayal G, Visser M, Zubakov D, Kayser M et al (2012) A multiplex (m)RNA-profiling system for the forensic identification of body fluids and contact traces. Forensic Sci Int Genet 6(5):565-577

25. Lindenbergh A, van den Berge M, Oostra RJ, Cleypool C, Bruggink A, Kloosterman A et al (2013) Development of a mRNA profiling multiplex for the inference of organ tissues. Int $\mathrm{J}$ Legal Med 127(5):891-900

26. Grabmüller M, Madea B, Courts C (2015) Comparative evaluation of different extraction and quantification methods for forensic RNA analysis. Forensic Sci Int Genet 16:195-202

27. Schroeder A, Mueller O, Stocker S, Salowsky R, Leiber M, Gassmann $\mathrm{M}$ et al (2006) The RIN: an RNA integrity number for assigning integrity values to RNA measurements. BMC Mol Biol 7:3

28. Hanson EK, Lubenow H, Ballantyne J (2009) Identification of forensically relevant body fluids using a panel of differentially expressed microRNAs. Anal Biochem 387(2):303-314

29. Courts C, Madea B (2011) Specific micro-RNA signatures for the detection of saliva and blood in forensic body-fluid identification. $\mathrm{J}$ Forensic Sci 56(6):1464-1470

30. Landgraf P, Rusu M, Sheridan R, Sewer A, Iovino N, Aravin A et al (2007) A mammalian microRNA expression atlas based on small RNA library sequencing. Cell 129(7):1401-1414

31. Peltier H, Latham GJ (2008) Normalization of microRNA expression levels in quantitative RT-PCR assays: identification of suitable reference RNA targets in normal and cancerous human solid tissues. RNA 14(5):844-852

32. Griffiths-Jones S (2004) The microRNA registry. Nucleic Acids Res 32:D109-D111

33. Vandesompele J, De Preter K, Pattyn F, Poppe B, Van Roy N, De Paepe A et al (2002) Accurate normalization of real-time quantitative RT-PCR data by geometric averaging of multiple internal control genes. Genome Biology 3:research0034.1

34. Anderson CJ, Jensen JL, Falck Ørntoft T (2004) Normalization of real-time quantitative reverse transcription-PCR data: a modelbased variance estimation approach to identify genes suited for normalization, applied to bladder and colon cancer data sets. Cancer Res 64(15):5245-5250

35. Pfaffl MW, Tichopad A, Prgomet C, Neuvians TP (2004) Determination of stable housekeeping genes, differentially regulated target genes and sample integrity: BestKeeper-Excel-based tool using pair-wise correlations. Biotechnol Lett 26(6):509-515

36. Sauer E, Madea B, Courts C (2014) An evidence based strategy for normalization of quantitative PCR data from miRNA expression analysis in forensically relevant body fluids. Forensic Sci Int Genet 11:174-181

37. Sauer E, Babion I, Madea B, Courts C (2014) An evidence based strategy for normalization of quantitative PCR data from miRNA expression analysis in forensic organ tissue identification. Forensic Sci Int Genet 13:217-223

38. Wong L, Lee K, Russell I, Chen C (2007) Endogenous controls for real-time quantitation of miRNA using TaqMan microRNA assays. Appl. Biosyst. TechNotes 127:11-01

39. Wang Z, Zhang J, Luo H, Ye Y, Yan J, Hou Y (2013) Screening and confirmation of microRNA markers for forensic body fluid identification. Forensic Sci. Int. Genet. 7(1):116-123

40. Zubakov D, Boersma AW, Choi Y, van Kuijk PF, Wiemer EA, Kayser, M (2010) MicroRNA markers for forensic body fluid identification obtained from microarray screening and quantitative RTPCR confirmation. Int J Legal Med 124(3):217-226

41. Ruijter JM, Ramakers C, Hoogaars WM, Karlen Y, Bakker O, van den Hoff MJ, et al (2009) Amplification efficiency: linking baseline and bias in the analysis of quantitative PCR data. Nucleic Acids Res 37(6): 45

42. Bustin SA, Benes V, Garson JA, Hellemans J, Huggett J, Kubista $\mathrm{M}$, et al (2009) The MIQE guidelines: minimum information for 
publication of quantitative real-time PCR experiments. Clin Chem 55(4):611-22

43. Hochmeister MN, Budowle B, Sparkes R, Rudin O, Gehrig C, Thali M, et al (1999) Validation studies of an immunochromatographic 1-step test for the forensic identification of human blood. J of Forensic Sci 44(3):597-602

44. Schneider PM (2009) Expansion of the European Standard Set of DNA database loci - the current situation. Profiles in DNA 12(1):67

45. Grabmüller M, Schyma C, Madea B, Eichhorst T, Courts C (2017) RNA/DNA co-analysis on aged bloodstains from adhesive tapes used for gunshot residue collection from hands. Forensic Sci Med Pathol. 13(2):161-169

46. Fleige S, Pfaffl MW (2006) RNA integrity and the effect on the real-time qRT-PCR performance. Mol Aspects of Med 27(2-3): 126-139

47. Jung M, Schaefer A, Steiner I, Kempkensteffen C, Stephan, Erbersdobler A, et al (2010) Robust microRNA stability in degraded RNA preparations from human tissue and cell samples. Clin. Chem. 56(6):998-1006

48. Hall JS, Taylor J, Valentine HR, Irlam JJ, Eustace A, Hoskin PJ, et al (2012) Enhanced stability of microRNA expression facilitates classification of FFPE tumour samples exhibiting near total mRNA degradation. Br J of Cancer 107(4):684-694

49. Becker C, Hammerle-Fickinger A, Riedmaier I, Pfaffl MW (2010) mRNA and microRNA quality control for RT-qPCR analysis. Methods 50(4):237-243

50. Fleige S, Walf V, Huch S, Prgomet C, Sehm J, Pfaffl MW (2006) Comparison of relative mRNA quantification models and the impact of RNA integrity in quantitative real-time RT-PCR. Biotechnology letters 28(19):1601-1613

51. Lux C, Schyma C, Madea B, Courts C (2014) Identification of gunshots to the head by detection of RNA in backspatter primarily expressed in brain tissue. Forensic Sci Int 237:62-69

52. Sauer E, Extra A, Cachée P, Courts C (2017) Identification of organ tissue types and skin from forensic samples by microRNA expression analysis. Forensic Sci Int Genet 28:99-110 